Article

\title{
Isoprenoids Production from Lipid-Extracted Microalgal Biomass Residues Using Engineered E. coli
}

\author{
Sumeng Wang and Jianming Yang * \\ Key Lab of Applied Mycology, College of Life Sciences, Qingdao Agricultural University, Qingdao 266109, \\ China; smwang001@126.com \\ * Correspondence: yjming888@126.com; Tel.: +86-532-8608-0640
}

Academic Editors: Robert M. Coates and Derek J. McPhee

Received: 20 April 2017; Accepted: 7 June 2017; Published: 9 June 2017

\begin{abstract}
Microalgae are recognized as a third generation feedstock for biofuel production due to their rapid growth rates and lignin-free characteristics. In this study, a lipid extracted microalgal biomass residues was used as the raw material to produce isoprene, $\alpha$-pinene and $\beta$-pinene with an engineered E. coli strain. We adopted an optimal sulfuric acid hydrolysis method (1:7 ratio of solid to acid solution, $32 \%(\mathrm{w} / \mathrm{v})$ concentration of sulfuric acid solution at $90{ }^{\circ} \mathrm{C}$ for $\left.90 \mathrm{~min}\right)$ to efficiently convert holocellulose into glucose efficiently $(6.37 \mathrm{~g} / \mathrm{L})$. Futhermore, we explored a novel detoxification strategy (phosphoric acid/calcium hydroxide) to remove inhibitors and notably acetic acid, furfural and 5-hydroxymethylfurfural (5-HMF) were reduced by 5.32\%, different number given later $99.19 \%$ and $98.22 \%$, respectively. Finally, the fermentation concentrations of isoprene $(223.23 \mathrm{mg} / \mathrm{L}), \alpha$-pinene $(382.21 \mu \mathrm{g} / \mathrm{L})$ and $\beta$-pinene $(17.4 \mathrm{mg} / \mathrm{L})$ were achieved using the detoxified hydrolysate as the carbon source, equivalent to approximately $86.02 \%, 90.16 \%$ and $88.32 \%$ of those produced by the engineered E. coli strain fermented on pure glucose, respectively.
\end{abstract}

Keywords: lipid extracted microalgae; isoprenoids; detoxification

\section{Introduction}

As the simplest member of isoprenoids, isoprene is an important platform chemical which could be used for producing medicines, pesticides, fragrances, and especially synthetic rubber [1-3]. Its derivatives, $\alpha$-pinene and $\beta$-pinene, therefore, have the potential to be used for aviation fuel production owing to their compact structures and reactive olefin functionality properties $[4,5]$. Currently, because of the structural complexity of isoprenoids, the reduced availability of fossil resources, and the rapid growth of microorganisms, there is potential for isoprenoids production using biosynthetic methods to replace chemical synthesis [4,5]. Nowadays, two biosynthesis pathways are used to produce isoprenoids: the MEP pathway used by many eubacteria, green algae, and the chloroplasts of higher plants, and the MVA pathway that mainly exists in eukaryotes, archaebacteria, and the cytosols of higher plants [4]. In this study, a heterologous MVA pathway was used to produce isoprene, $\alpha$-pinene and $\beta$-pinene with suitably engineered E. coli strains (YJM25, YJM29, FHR-2, respectively). However, due to the bottleneck of feedstock availability, biotechnology need to be applied to isoprenoids production by using more economical resources.

Initially, starch (potato, wheat etc.) was used as the first generation feedstock to produce bioethanol and other biobased materials. However, large amounts of crops are consumed during the fermentation, which could lead to severe food shortages, especially in the developing countries [6]. Later, in the past two decades, second generation feedstocks, lignocellulosic materials (straw, wood and grass) have been explored in biofuel production since they are cheap, renewable and don't have 
compete with food supplies. These second generation materials are not applied to commercially due to their low yield and high cost resulting from the necessary hydrolysis process [6,7]. Therefore, a third generation feedstock is required to both satisfy the demand for biofuel production on a large scale and maintain ecological balance at the same time. Currently, some researchers have proposed algae as an ideal alternative for biofuel production due to its rapid growth, a unicellular or simple multicellular structure, lignin-free properties and ready availability on Earth [8].

Hence, in this paper, we utilized the lipid extracted microalgal biomass residues (LMBRs) as the feedstock to biosynthesize isoprene and its derivatives ( $\alpha$-pinene and $\beta$-pinene) using the engineered E. coli. This began with the conversion of LMBRs into fermentable sugar, and then the microbial fermentation was performed to generate bio-based isoprenoids. However, as it is rather time- and money-consuming, the LMBRs were hydrolyzed with sulfuric acid rather than enzymatic hydrolysis. Finally, $6.37 \mathrm{~g} / \mathrm{L}$ of glucose was achieved based on the following hydrolysis conditions: ratio of solid to acid (1:7), acid concentration $(32 \%)$, hydrolysis temperature $\left(90^{\circ} \mathrm{C}\right)$, and hydrolysis time $(90 \mathrm{~min})$. Since fermentation inhibitors (weak acid, furfural, 5-HMF) were formed during the acid hydrolysis process [6], we adopted five different detoxification strategies with recombination to reduce the inhibition consequence on the fermentation [6-10]. Among five methods, the phosphoric acid/calcium hydroxide detoxification combination, the best detoxification approach, was applied to remove acetic acid, furfural and 5-HMF by about 55.32\%, 99.19\% and 98.22\% respectively. Finally, $223.23 \mathrm{mg} / \mathrm{L}$ of isoprene, $382.21 \mu \mathrm{g} / \mathrm{L}$ of $\alpha$-pinene and $17.4 \mathrm{mg} / \mathrm{L}$ of $\beta$-pinene were obtained from the engineered E. coli strain fermented on the detoxified hydrolysate of LMBRs, accounting for about $86.02 \%, 90.16 \%$ and $88.32 \%$, respectively, of the isoprene, $\alpha$-pinene and $\beta$-pinene production by the $E$. coli strain using pure glucose, respectively.

\section{Results and Discussion}

\subsection{Chemical Composition of LMBRs}

As is shown in Figure 1, in a given $100 \mathrm{~g}$ amount of LMBRs, using appropriate quantification methods, there are about $18.03 \mathrm{~g}$ of holocellulose, $48.12 \mathrm{~g}$ of protein, $24.35 \mathrm{~g}$ of ash, $0.28 \mathrm{~g}$ of lipid and $9.22 \mathrm{~g}$ of water. Compared to the total lipid content (30-36 g) of microalgae in the previous study [11], this suggestes that the lipid in LMBRs has been almost completely extracted. What is more encouraging is that no lignin was found, as this represents most unfavorable threat to lignocellulose hydrolysis rejection, and therefore it must be removed prior to hydrolysis [12]. As we all know, to get rid of lignin during the process of pretreatment is rather costly and time-consuming as well. Hence, compared with lignocellulose (rice straw, switchgrass, etc.), LMBRs (with its absence of lignin) is considered an ideal alternative as the biofuel-producing material [13].

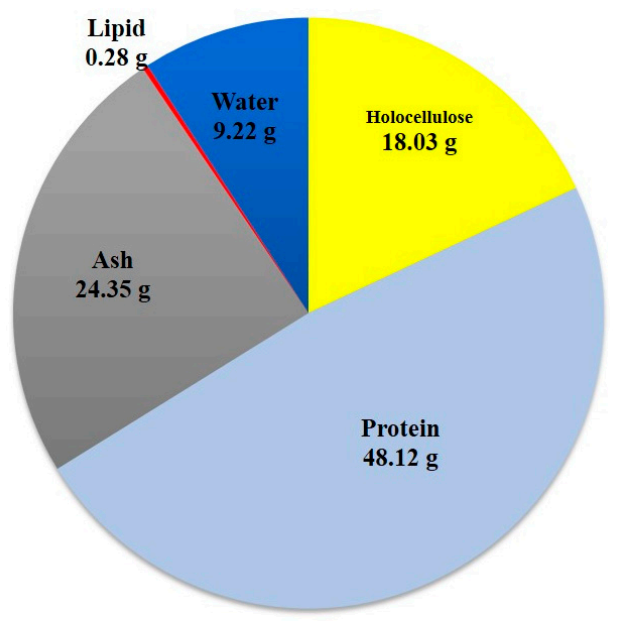

Figure 1. Chemical composition content of $100 \mathrm{~g}$ lipid extracted microalgae biomass. 


\subsection{Optimization of Acid Hydrolysis Condition}

In this study, the "one-factor at-a-time" optimization strategy was applied to augment the hydrolytic efficiency by optimizing time, temperature, acid concentration and ratio of solid to acid solution respectively [14,15]. Figure 2 shows that the maximal glucose concentration $(6.37 \mathrm{~g} / \mathrm{L})$ was obtained under the hydrolysis condition of $1: 7$ ratio of solid to acid solution, 32\% $(w / v)$ concentration of sulfuric acid solution at $90{ }^{\circ} \mathrm{C}$ for $90 \mathrm{~min}$. The combined optimization effect could contribute to an approximately 142 -fold increase in glucose concentration.
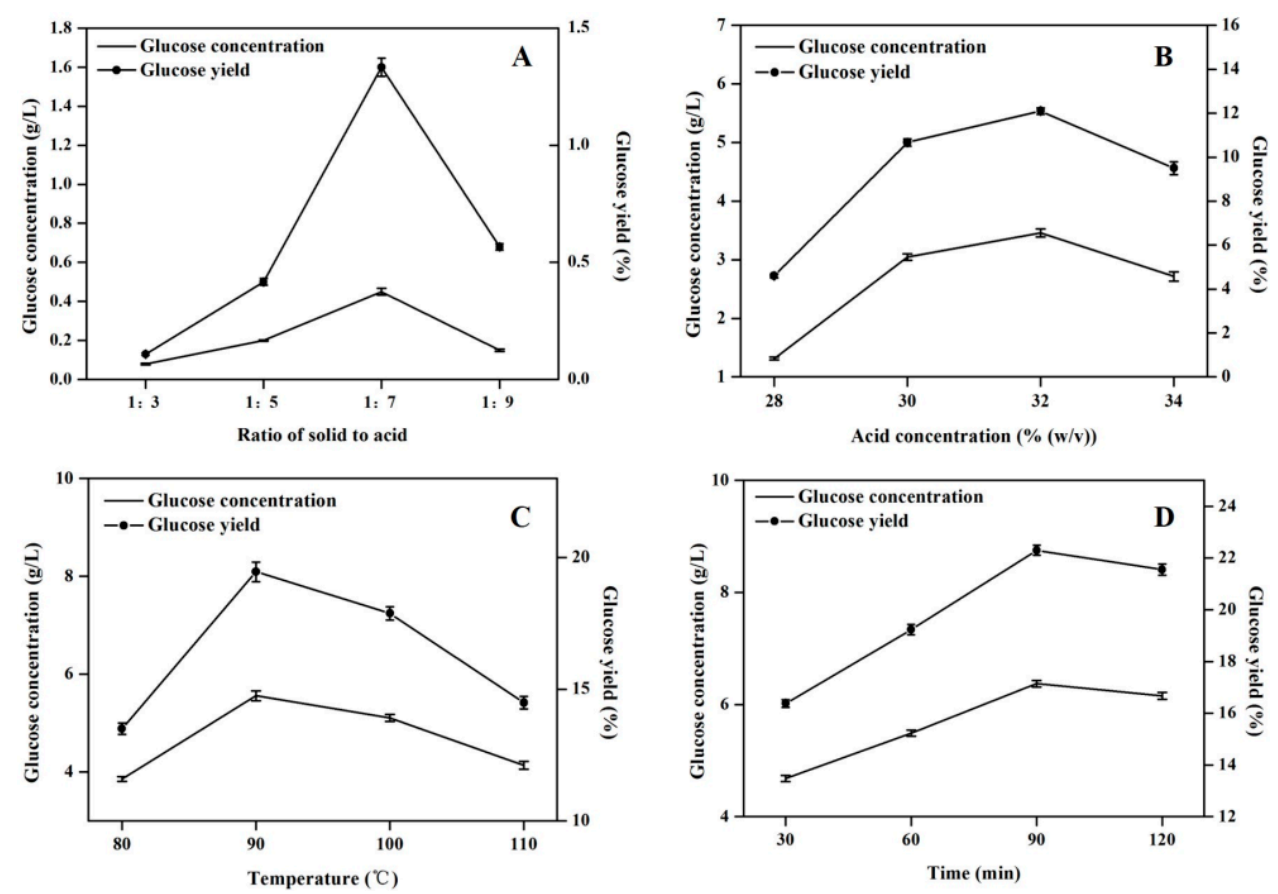

Figure 2. Effects of acid hydrolysis conditions on the glucose concentration and yield. (A) Effect of ratio of solid to acid on acid hydrolysis efficiency; (B) Effect of concentration of sulfuric acid on acid hydrolysis efficiency; (C) Effect of temperature on acid hydrolysis efficiency; (D) Effect of reaction time on acid hydrolysis efficiency. The experiment was performed in triplicate.

\subsection{Inhibitor Changes with Different Detoxification Methods}

The acidolysis reaction could not only converts the lignocellulose into fermentable monomeric sugar, but some by-products (weak acid, furfural and 5-HMF, etc.) were also formed simultaneously. These by-products could inhibit the microorganism from producing high value-added products [16]. Due to absence of lignin in the LMBRs, only three main inhibitors including acetic acid, furfural and $5-\mathrm{HMF}$, would be produced during the acidolysis process. Acetic acid is formed primarily by hydrolysis of acetate groups of the acetate hemicellulose. While furfural and 5-HMF are derived from pentoses and hexoses, respectively [17].

To date, many of investigations have shown that neutralization, overliming, activated charcoal, ion exchange resin and reducing agents all have the ability to remove the inhibitors from the acidolysis hydrolysate [6-10]. In the present study, we adopted five different kinds of detoxification strategies to explore the optimal detoxification method and analyzed the changes in the concentration of three types of inhibitors (acetic acid, furfural and 5-HMF). As is shown in Figure 3, compared with the raw hydrolysate, the concentration of all three types of inhibitors was reduced more or less in five different detoxification hydrolyzates. 


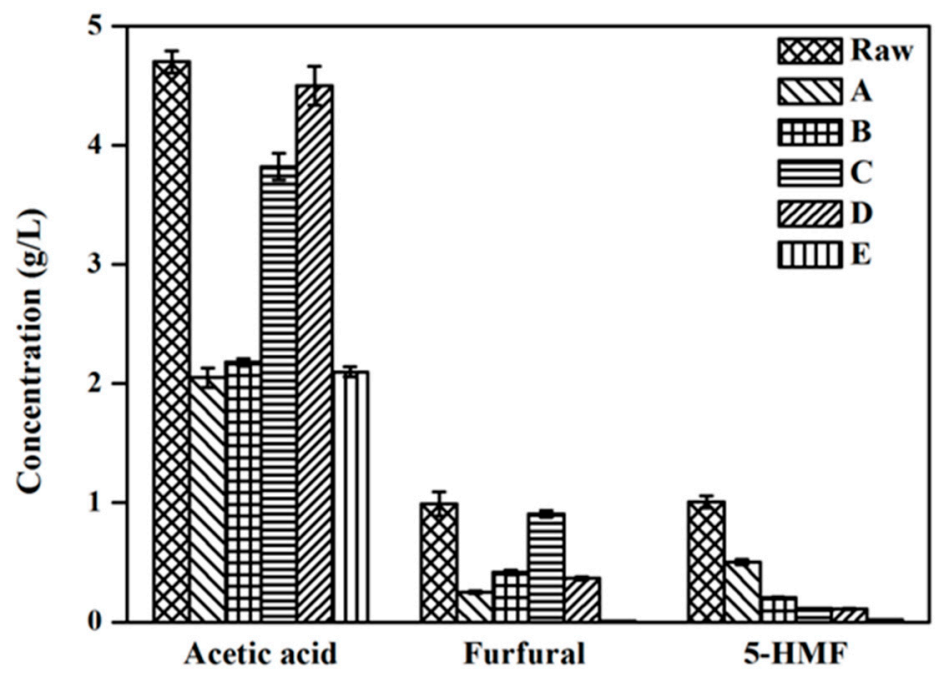

Figure 3. Inhibitors concentration of raw and detoxification hydrolysates with A-E five different detoxification strategies. These five detoxification methods are corresponding to the five methods A-E described in the Materials and Methods section, respectively. The experiments were performed in triplicate.

Though methods A and B could decrease the acetic acid volume by more than half, the concentration of the furfural and 5-HMF inhibitors still remains too high. The hydrolysates after detoxification by methods $C$ and $D$ have a lower 5-HMF concentration, however, the acetic acid of the two hydrolysates was barely removed. Interestingly, in the detoxification hydrolysate using method E method, the acetic acid, furfural and 5-HMF were reduced about $55.32 \%, 99.19 \%$ and $98.22 \%$, respectively. It showed that $\mathrm{E}$ detoxification method was the most efficient in the simultaneous removal of the three abovementioned inhibitors simultaneously. Meanwhile, compared with other detoxification methods, E method also presented a series of advantages such as lower cost, and easier operation in addition to the better capacity to remove inhibitory compounds. As a result, when cost, removal efficiency and difficulty of the detoxification process are all taken into consideration, method $\mathrm{E}$ has the highest potential to be used in the future industrialization field.

\subsection{Effect of Detoxification on Isoprenoids Production}

Figure 4 has presents the isoprene produced by the engineeried E. coli YJM25 with seven different carbon sources, including pure glucose, raw hydrolysate, and hydrolysates detoxified by methods A-E. As can be seen, compared with the raw hydrolysate fermentation $(160.26 \mathrm{mg} / \mathrm{L})$, isoprene yield produced by using group E hydrolysate $(223.23 \mathrm{mg} / \mathrm{L})$ was increased by about $40 \%$ after the $\mathrm{E}$ detoxification. The concentration of isoprene produced by group $\mathrm{E}$ hydrolysate represented $86.02 \%$ of that produced using pure glucose $(259.52 \mathrm{mg} / \mathrm{L})$. This percentage is much higher than those obtained using the other five types of hydrolysate (treatments A-D and raw). Therefore, the calcium hydroxide/phosphoric acid detoxification method was proved to be better than the other four kinds of detoxification methods for isoprene production with E. coli. As is expected, Figures 5 and 6 have also demonstrated that, in comparision to raw hydrolysate fermentation, the yield of $\alpha$-pinene and $\beta$-pinene were increased about $35 \%$ and $52 \%$, respectively, when using hydrolysate detoxified by method $E$ and $\alpha$-pinene and $\beta$-pinene production accounted for about $90.16 \%$ and $88.32 \%$ of the yield produced on pure glucose. These results revealed that the $E$. coli fermentability was improved greatly after using the calcium hydroxide/phosphoric acid detoxification strategy. 


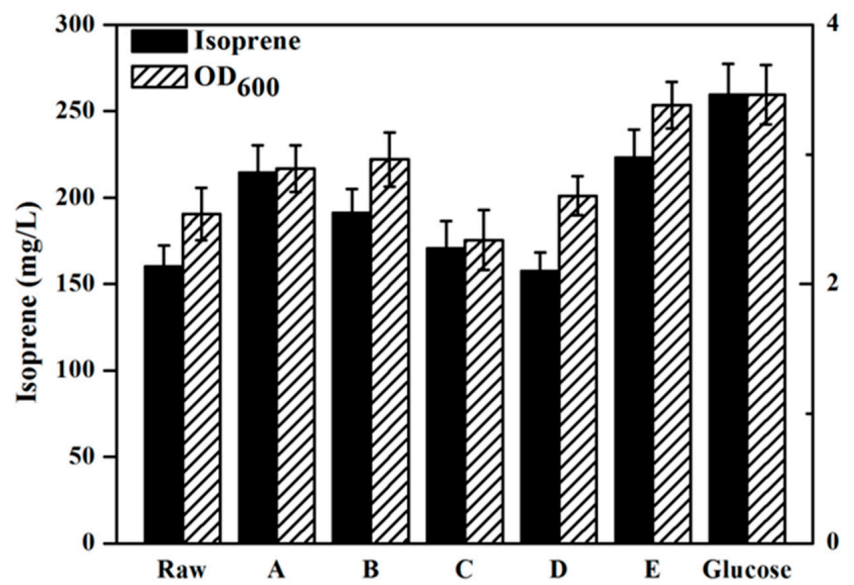

Figure 4. Isoprene production by the YJM25 strain using different carbon sources containing pure glucose, raw hydrolysate and five different kinds of hydrolysates detoxified by methods A-E. When $\mathrm{OD}_{600}$ reached $\sim 0.6$, cultures was induced at $30^{\circ} \mathrm{C}$ for $24 \mathrm{~h}$ using $0.5 \mathrm{mM}$ IPTG. The experiments were performed in triplicate.

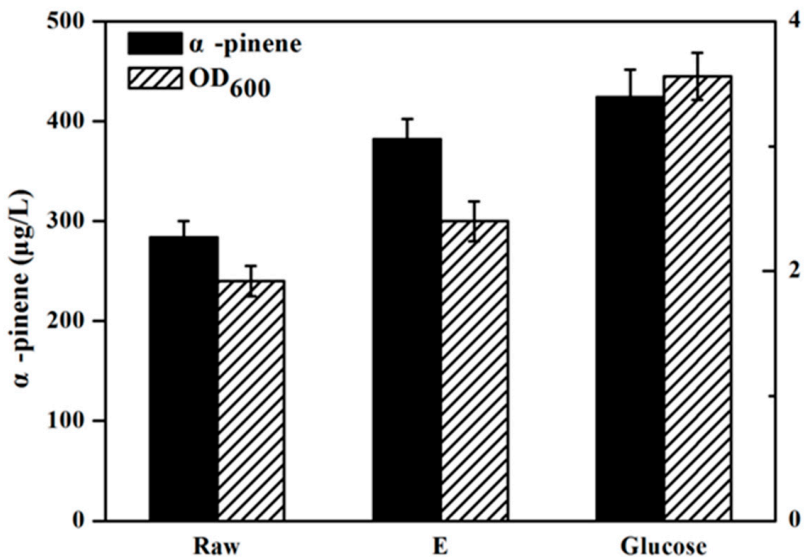

Figure 5. $\alpha$-Pinene production by the YJM29 strain using different carbon sources containing pure glucose, raw hydrolysate and hydrolysate detoxified by method E. When $\mathrm{OD}_{600}$ reaches $\sim 0.6$, cultures were induced at $30{ }^{\circ} \mathrm{C}$ for $24 \mathrm{~h}$ using $0.5 \mathrm{mM}$ IPTG. The experiments were performed in triplicate.

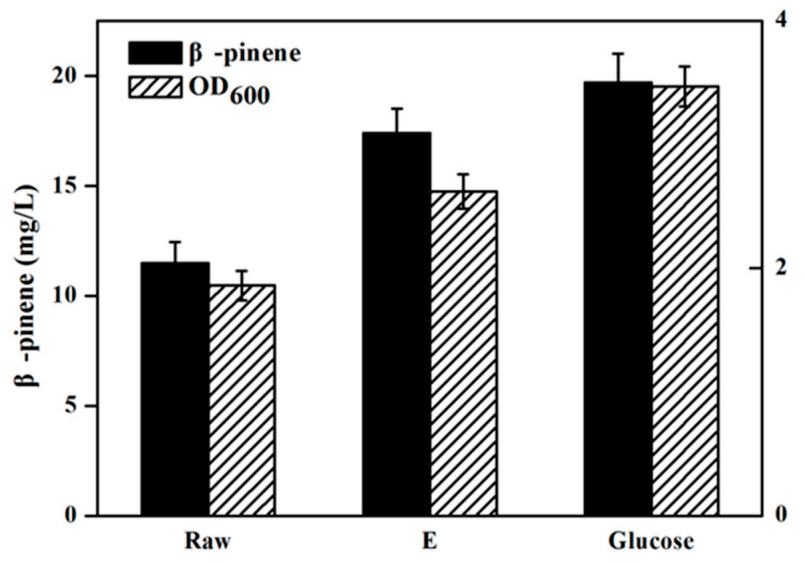

Figure 6. $\beta$-Pinene production by strain FHR-2 using different carbon sources containing pure glucose, raw and hydrolysate detoxified by method $\mathrm{E}$. When $\mathrm{OD}_{600}$ reaches $\sim 0.6$, cultures were induced at $30{ }^{\circ} \mathrm{C}$ for $24 \mathrm{~h}$ using $0.5 \mathrm{mM}$ IPTG. The experiments were performed in triplicate. 
Microorganism growth can be restricted by toxic inhibitive compounds such as furfurals, 5-HMF and organic acids [18]. Among those inhibitors, furfural was found to be able to inactivate the cell replication by breaking down the single-strand DNA [19-22]. Organic acids (acetic acid) derived from hemicellulose could cross the cell membrane, which resulted in a lower cell $\mathrm{pH}$ than normal and consequently inhibited cell activity [21,23]. Ultimately, the cell activity of E. coli was inhibited and this directly reduced its fermentation ability. As shown in Figures 3 and 4, compared to other different carbon sources, the hydrolysate subjected to detoxification method $\mathrm{E}$ had the lowest concentration of inhibitors and consequently achieved the highest isoprene yield.

Chandra et al. have reported that although the toxicity of acetic acid on microorganisms is lower thanthat of furans (furfural and 5-HMF), the synergistic toxicity is possibly more severe when furans are present in conjunction with acetic acid [18]. In this study, we observed a similar result: as shown in Figures 3 and 4, the amount of acetic acid in both hydrolysates detoxified by methods $\mathrm{A}$ and $\mathrm{E}$ was similar while that of the furans was higher in hydrolysate A than in hydrolysate $\mathrm{E}$, which resulted in a lower isoprene production from hydrolysate $\mathrm{A}$ than with hydrolysate $\mathrm{E}$, suggesting that the reason for the lower isoprene production from hydrolysate A might be a synergistic toxicity of acetic acid and furans.

\section{Methods and Materials}

\subsection{Materials}

LMBRs used in this study, which were the residual Chlorella biomass derived from oil extraction processes [11], were kindly provided by Prof. Tianzhong Liu (Qingdao Institute of Bioenergy and Bioprocess Technology, Chinese Academy of Sciences, Qingdao, China). Briefly, algae was mixed with ethanol at $1.5 \mathrm{MPa}, 120^{\circ} \mathrm{C}$ for $50 \mathrm{~min}$ and after cooling to room temperature, the residual algae and the oil solution was separated with centrifugation. Finally, the residual algae was collected to be used in this study. LMBRs were oven dried at $60^{\circ} \mathrm{C}$ and milled to 60 mesh size. Sulfuric acid $\left(\mathrm{H}_{2} \mathrm{SO}_{4}\right)$, sodium hydroxide $(\mathrm{NaOH})$, calcium hydroxide $\left(\mathrm{Ca}(\mathrm{OH})_{2}\right)$ and phosphoric acid $\left(\mathrm{H}_{3} \mathrm{PO}_{4}\right)$ were bought from Sinopharm Chemical Reagent Co., Ltd. (Shanghai, China). Ion exchange resin (D310) was purchased from Tianjin Nankai University resin company (Tianjin, China). All of chemical reagents were analytical reagent grade.

\subsection{Compositions Analysis}

The compositions of LMBRs were determined using previously repoerted methods. Cellulose and hemicellulose were analyzed according to the method of NREL Laboratory Analytical Procedure (LAP) method [24]. In this study, LMBRs (300 mg) was treated with $72 \%$ sulfuric acid ( $3 \mathrm{~mL}$ ) at $30{ }^{\circ} \mathrm{C}$ for 60 min. And then, deionized water $(84 \mathrm{~mL})$ was added into the mixture to dilute the sulfuric acid to a $4 \%$ concentration. The reaction mixture was incubated at $121^{\circ} \mathrm{C}$ for $60 \mathrm{~min}$. After cooling the mixture to room temperature, the residue was removed by filtration and the supernatant was collected and determined by HPLC to measure the monomeric sugar content including glucose, xylose, arabinose, galactose and mannose. The concentration of cellulose and hemicellulose were calculated according to the monomeric sugar content.

Total protein was measured based on the a previous study [25]. The nitrogen content was detected using an elemental analyzer (Elementar Vario EL III, Elementar Co., Hanau, Germany). Then, the crude protein concentration was calculated by the following formula:

$$
\text { protein concentration }=\text { nitrogen content } \times 6.25 \text {. }
$$

Lipid content was determined according to Lin Chen's study using the gravimetric analysis method [11]. Dried algae (100 mg) was added into chloroform/methanol $(1: 2, v / v, 5 \mathrm{~mL})$ and incubated at $65{ }^{\circ} \mathrm{C}$ for $1 \mathrm{~h}$. After cooling the mixture to room temperature, the supernatant was separated from the LMBRs residue. This process was repeated three times. Then the three supernatants were combined 
into a vessel, the solution was dried and the lipid content was calculated by combining the dry weight of residue and the total LMBRs.

Ash analysis of LMBRs was measured according to the NREL Laboratory Analytical Procedure (LAP) [26]. LMBRs $(1.0 \mathrm{~g})$ was put in a crucible and incubated at $575 \pm 25^{\circ} \mathrm{C}$ for $24 \mathrm{~h}$. After the sample and crucible were cooled to room temperature in a desiccator, they were weighed accurately. The ash content was determined according to the gravimetric method.

Organic solvent extractives (O.S.E) were analyzed by the TAPPI Standard Methods [27]. O.S.E of LMBRs was extracted by using a Soxhlet extraction apparatus, then the extractive was dried at $105 \pm 3{ }^{\circ} \mathrm{C}$ to determine the O.S.E content was calculated according to the percentage of the extractive to unextracted LMBRs. The aqueous component was measured by the gravimetric method after drying the samples completely.

\subsection{Optimization of the Acid Hydrolysis Process}

Four kinds of factors that affect the acid hydrolysis were optimized with four kinds of factors including time, temperature, and concentration of sulfuric acid and the ratio of solid to acid. After lipid-extracting, the recovering microalgae residues was collected by filtration, then, the residues was washed with distilled water until the $\mathrm{pH}$ reached neutral and dried at $60{ }^{\circ} \mathrm{C}$. The hydrolysis procedure was optimized as shown in Table 1 . And the glucose concentration was detected and calculated by comparison with a standard using HPLC. All of experiments were repeated three times.

Table 1. Exploration of the four kinds of hydrolysis condition was explored at four kinds of factors of LMBRs.

\begin{tabular}{ccc}
\hline Optimization Factor & Range of Optimization Factor & Constant Factors \\
\hline Ratio of solid to acid & $1: 3,1: 5,1: 7,1: 9$ & $\begin{array}{c}20 \%(w / v) \text { concentration of sulfuric acid solution, } \\
\text { at } 80{ }^{\circ} \mathrm{C} \text { for } 30 \text { min }\end{array}$ \\
\hline Concentration of sulfuric acid & $\begin{array}{c}28 \%(w / v), 30 \%(w / v), 32 \%(w / v), \\
34 \%(w / v)\end{array}$ & $1: 7$ ratio of solid to acid solution, at $80{ }^{\circ} \mathrm{C}$ for $30 \mathrm{~min}$ \\
\hline temperature & $80{ }^{\circ} \mathrm{C}, 90{ }^{\circ} \mathrm{C}, 100{ }^{\circ} \mathrm{C}, 110{ }^{\circ} \mathrm{C}$ & $\begin{array}{c}1: 7 \text { ratio of solid to acid solution and } 32 \%(w / v) \\
\text { concentration of sulfuric acid solution for } 30 \mathrm{~min}\end{array}$ \\
\hline Time & $30 \mathrm{~min}, 60 \mathrm{~min}, 90 \mathrm{~min}, 120 \mathrm{~min}$ & $\begin{array}{c}1: 7 \text { ratio of solid to acid solution and } 32 \%(w / v) \\
\text { concentration of sulfuric acid solution, at } 900^{\circ} \mathrm{C}\end{array}$ \\
\hline
\end{tabular}

\subsection{Inhibitor and Sugar Analysis of the Hydrolysates}

Inhibitors and glucose were analyzed using HPLC equipped with a refractive index (RID) detector, and the concentration of inhibitors and glucose were calculated by converting peak areas to gram weights via their calibration curves. The HPX-87 Bio-Rad Aminex Column (300 mm $\times 7.8 \mathrm{~mm}$, Bio-Rad, Hercules, CA, USA) was used for glucose detection. $0.005 \mathrm{M}$ sulfuric acid was used as the mobile phase with a flow rate of $0.6 \mathrm{~mL} / \mathrm{min}$, and the column temperature was $55^{\circ} \mathrm{C}$. The concentrations of furfural and 5-HMF were determined with C-18 column (Nucleosil 100-5 C18, Merck, Darmstadt, Germany) with a gradient of $5-100 \%(v / v)$ methanol and $0.025 \%(v / v)$ of trifluoroacetic acid with a flow rate of $0.8 \mathrm{~mL} / \mathrm{min}$; formic acid and acetic acid were determined with AS11HC column which was eluted with $80 \%(v / v)$ water and $20 \%(v / v)$ of a mixture consisting of $0.4 \mathrm{mM} \mathrm{NaOH}$ and methanol $(50 \%$ $v / v)$ at a flow rate of $1.4 \mathrm{~mL} / \mathrm{min}[6]$.

\subsection{Detoxification}

To produce isoprenoids with engineered E. coli, inhibitors that would be generated when the microalgae biomass is hydrolyzed with sulfuric acid should be removed first. As is shown in the following, five strategies have been developed to remove the inhibitors in the acidolysis hydrolysate based on previous studies with some modifications [6-10]: 
A. The hydrolysate was adjusted to $\mathrm{pH} 10$ with sodium hydroxide, and then the solution was readjusted with sulfuric acid to $\mathrm{pH} 5$. Anhydrous sodium sulphite $(1 \mathrm{~g} / \mathrm{L})$ was added to the solution which was heated to $100{ }^{\circ} \mathrm{C}$ for $15 \mathrm{~min}$. Then, $1 \%(w / v)$ activated carbon was mixed into the solution and incubated at $40{ }^{\circ} \mathrm{C}$ with shaking at $200 \mathrm{rpm}$ for $1 \mathrm{~h}$.

B. The hydrolysate was neutralized with calcium hydroxide. After that, $1 \%(w / v)$ activated carbon was added into the solution and incubated at $40^{\circ} \mathrm{C}$ with shaking at $200 \mathrm{rpm}$ for $1 \mathrm{~h}$.

C. Sodium hydroxide was used to regulate the $\mathrm{pH}$ of the hydrolysate to 5.0 , and then $1 \%(w / v)$ activated carbon was added into the solution and incubated $40{ }^{\circ} \mathrm{C}$ with shaking at $200 \mathrm{rpm}$ for $1 \mathrm{~h}$.

D. Anion exchange resin (D301, Tianjin, China) was added to the hydrolysate with the loading concentration of $20 \%(w / v)$ until the $\mathrm{pH}$ reached 5.5. The mixed solution was kept at $24{ }^{\circ} \mathrm{C}$, with shaking $200 \mathrm{rpm}$ for $1 \mathrm{~h}$.

E. The $\mathrm{pH}$ of the hydrolysate was initially adjusted to 7.0 with calcium hydroxide, after that, the $\mathrm{pH}$ was readjusted to 5.5 with phosphoric acid.

All of the hydrolysated were filtered with a vacuum filter to obtain the supernatant after the inhibitors were removed with the different detoxification methods.

\subsection{Biosynthesis and Analysis of Isoprenoids Produced Using the Engineered E. coli Strains}

To verify whether the hydrolysate of LMBRs could be utilized to produce bio-based chemicals, several engineered E. coli strains were employed to produce isoprenoids. YJM25 (E. coli BL21 ${ }^{\mathrm{TM}}$ (DE3)/pYJM21, pYJM14), containing the optimized pathway and isoprene synthase, was used for isoprene fermentation [4]. YJM29 (E. coli BL21(DE3)/pYJM28), harboring a more efficient pathway for $\alpha$-pinene production with the heterologous hybrid MVA pathway, GPPS2 and $\alpha$-pinene synthase (Pt30), was utilized in $\alpha$-pinene biosynthesis [5]. And FHR-2, including the Artemisia annua $\beta$-pinene synthase gene (QH6) and a heterologous hybrid mevalonate (MVA) pathway (E. coli BL21 (DE3) (pACYDuet-1-mvaE-mvaS-GPPS2-QH6, pTrcHis2B-ERG8-ERG12-ERG19-IDI1), was applied for $\beta$-pinene production [28]. The fermentation procedure was carried out as reported in the previous study [29] with some modifications. Shake-flask experiments were performed in triplicate using a series of sealed $600 \mathrm{~mL}$ shake flasks containing $100 \mathrm{~mL}$ of fermentation medium including glucose $2 \mathrm{~g} / \mathrm{L}$ or a suitable concentration of acid hydrolysates. Optical density (OD) of the bacteria was measured with a spectrophotometer (Cary-50, Varian Inc., Palo Alto, CA, USA) at a wavelength of $600 \mathrm{~nm}$. The isoprene, $\alpha$-pinene and $\beta$-pinene production were analyzed as described earlier $[4,5,28]$ by a gas chromatograph (GC) equipped with a flame ionization detector (FID) and a HP-1 column ( $30 \mathrm{~m} \times 0.25 \mathrm{~mm} \times 0.25 \mu \mathrm{m}$, Agilent, Palo Alto, CA, USA). Based on the retention time of standard samples, isoprene, $\alpha$-pinene and $\beta$-pinene were identified, respectively. The concentration of target production was calculated from the peak area using a standard curve.

\section{Conclusions}

LMBRs are a potential raw material for biofuel production due to their absence of lignin and the presence of fermentable sugar in the microalgal residual biomass. $6.37 \mathrm{~g} / \mathrm{L}$ glucose was achieved after hydrolyzing the lipid extracted microalgae with $1: 7$ ratio of solid to acid solution, $32 \%(w / v)$ concentration of sulfuric acid at $90^{\circ} \mathrm{C}$ for $90 \mathrm{~min}$. In order to increase the production of isoprene, $\alpha$-pinene and $\beta$-pinene, inhibitors including acetic acid, furfural and 5-HMF of acid hydrolysate were removed by about $55.32 \%, 99.19 \%$ and $98.22 \%$, respectively, by a new method (phosphoric acid/calcium hydroxide). Finally, $223.23 \mathrm{mg} / \mathrm{L}$ isoprene, $382.21 \mu \mathrm{g} / \mathrm{L} \alpha$-pinene and $17.4 \mathrm{mg} / \mathrm{L}$ $\beta$-pinene were produced, which representted about $86.02 \%, 90.16 \%$ and $88.32 \%$ of the quantities produced by pure glucose fermentation, respectively. Therefore, lipid extracted microalgae can be regarded as a promising material for the production of isoprenoids and other bio-based chemicals. 
Acknowledgments: The authors appreciate Tianzhong Liu for providing the LMBRs. This work was financially supported by the Natural Science Foundation of Shandong Province, China (Grant No. ZR2015BM021), the National Natural Science Foundation of China (Grant No. 21572242), the Project of Science and Technology for People's Livelihood of Qingdao (No. 15-9-2-94-nsh), the special project of science and technology development for construction (Grant No. JK2015-22), the Talents of High Level Scientific Research Foundation (Grant No. 6631113326) of Qingdao Agricultural University, the National Natural Science Foundation of China (Grant No. 31300599), the Talents of High Level Scientific Research Foundation (Grant No. 6631113318) of Qingdao Agricultural University, and the National Natural Science Foundation of China (Grant No. 31172012/c1506).

Author Contributions: J.Y. conceived and designed the experiments; S.W. performed the experiments and analyzed the data; S.W. wrote the paper and J.Y. revised the paper. All authors read and approved the final manuscript.

Conflicts of Interest: The authors declare no conflict of interest.

\section{References}

1. Zhao, Y.; Yang, J.; Qin, B.; Li, Y.; Sun, Y.; Su, S.; Xian, M. Biosynthesis of isoprene in Escherichia coli via methylerythritol phosphate (MEP) pathway. Appl. Microbiol. Biotechnol. 2011, 90, 1915-1922. [CrossRef] [PubMed]

2. Alianell, G.A.; Derwitsch, F.; Wells, D.; Taylor, T. Isoprene Compositions and Methods of Use. U.S. Patent US20100099932 A1, 22 April 2010.

3. Kesselmeier, J.; Staudt, M. Biogenic volatile organic compounds (VOC): An overview on emission, physiology and ecology. J. Atmos. Chem. 1999, 33, 23-88. [CrossRef]

4. Yang, J.; Xian, M.; Su, S.; Zhao, G.; Nie, Q.; Jiang, X.; Zheng, Y.; Liu, W. Enhancing production of bio-isoprene using hybrid MVA pathway and isoprene synthase in E. coli. PLoS ONE 2012, 7, e33509. [CrossRef] [PubMed]

5. Yang, J.; Nie, Q.; Ren, M.; Feng, H.; Jiang, X.; Zheng, Y.; Liu, M.; Zhang, H.; Xian, M. Metabolic engineering of Escherichia coli for the biosynthesis of alpha-pinene. Biotechnol. Biofuels 2013, 6, 60. [CrossRef] [PubMed]

6. Larsson, S.; Reimann, A.; Nilvebrant, N.-O.; Jönsson, L.J. Comparison of different methods for the detoxification of lignocellulose hydrolyzates of spruce. Appl. Biochem. Biotechnol. 1999, 77, 91-103. [CrossRef]

7. Agblevor, F.; Fu, J.; Hames, B.; McMillan, J. Identification of microbial inhibitory functional groups in corn stover hydrolysate by carbon-13 nuclear magnetic resonance spectroscopy. Appl. Biochem. Biotechnol. 2004, 119, 97-120. [CrossRef]

8. Canilha, L.; de Almeida e Silva, J.B.; Solenzal, A.I.N. Eucalyptus hydrolysate detoxification with activated charcoal adsorption or ion-exchange resins for xylitol production. Process Biochem. 2004, 39, 1909-1912. [CrossRef]

9. Martinez, A.; Rodriguez, M.E.; York, S.W.; Preston, J.F.; Ingram, L.O. Effects of $\mathrm{Ca}(\mathrm{OH}) 2$ treatments (overliming) on the composition and toxicity of bagasse hemicellulose hydrolysates. Biotechnol. Bioeng. 2000, 69, 526-536. [CrossRef]

10. Mpabanga, T.P.; Chandel, A.K.; da Silva, S.S.; Singh, O.V. Detoxification Strategies Applied to Lignocellulosic Hydrolysates for Improved Xylitol Production. In D-Xylitol; Springer: Cham, Switzerland, 2012; pp. 63-82.

11. Chen, L.; Liu, T.; Zhang, W.; Chen, X.; Wang, J. Biodiesel production from algae oil high in free fatty acids by two-step catalytic conversion. Bioresour. Technol. 2012, 111, 208-214. [CrossRef] [PubMed]

12. Hu, F.; Ragauskas, A. Pretreatment and lignocellulosic chemistry. Bioenergy Res. 2012, 5, $1043-1066$. [CrossRef]

13. Harun, R.; Danquah, M.K. Influence of acid pre-treatment on microalgal biomass for bioethanol production. Process Biochem. 2011, 46, 304-309. [CrossRef]

14. Wi, S.G.; Cho, E.J.; Lee, D.-S.; Lee, S.J.; Lee, Y.J.; Bae, H.-J. Lignocellulose conversion for biofuel: A new pretreatment greatly improves downstream biocatalytic hydrolysis of various lignocellulosic materials. Biotechnol. Biofuels 2015, 8, 228. [CrossRef] [PubMed]

15. Jung, Y.H.; Kim, I.J.; Kim, H.K.; Kim, K.H. Dilute acid pretreatment of lignocellulose for whole slurry ethanol fermentation. Bioresour. Technol. 2013, 132, 109-114. [CrossRef] [PubMed]

16. Parawira, W.; Tekere, M. Biotechnological strategies to overcome inhibitors in lignocellulose hydrolysates for ethanol production: Review. Crit. Rev. Biotechnol. 2011, 31, 20-31. [CrossRef] [PubMed]

17. Jönsson, L.J.; Alriksson, B.; Nilvebrant, N.-O. Bioconversion of lignocellulose: Inhibitors and detoxification. Biotechnol. Biofuels 2013, 6, 16. [CrossRef] [PubMed] 
18. Chandel, A.K.; Singh, O.V.; da Silva, S.S. Detoxification of Lignocellulosic Hydrolysates for Improved Bioethanol Production. In Biofuel Production-Recent Developments and Prospects; INTECH Open Access Publisher: Rijeka, Croatia, 2011.

19. Palmqvist, E.; Almeida, J.S.; Hahn-Hägerdal, B. Influence of furfural on anaerobic glycolytic kinetics of Saccharomyces cerevisiae in batch culture. Biotechnol. Bioeng. 1999, 62, 447-454. [CrossRef]

20. Taherzadeh, M.J.; Gustafsson, L.; Niklasson, C.; Lidén, G. Conversion of furfural in aerobic and anaerobic batch fermentation of glucose by Saccharomyces cerevisiae. J. Biosci. Bioeng. 1999, 87, 169-174. [CrossRef]

21. Palmqvist, E.; Hahn-Hägerdal, B. Fermentation of lignocellulosic hydrolysates. II: Inhibitors and mechanisms of inhibition. Bioresour. Technol. 2000, 74, 25-33. [CrossRef]

22. Mills, T.Y.; Sandoval, N.R.; Gill, R.T. Cellulosic hydrolysate toxicity and tolerance mechanisms in Escherichia coli. Biotechnol. Biofuels 2009, 2, 1. [CrossRef] [PubMed]

23. Chandel, A.K.; Da Silva, S.S.; Singh, O.V. Detoxification of lignocellulose hydrolysates: Biochemical and metabolic engineering toward white biotechnology. Bioenergy Res. 2013, 6, 388-401. [CrossRef]

24. Sluiter, A.D.; Hames, B.; Ruiz, R.O.; Scarlata, C.; Sluiter, J.; Templeton, D.W.; Crocker, D. Determination of structural carbohydrates and lignin in biomass. Lab. Anal. Proced. 2008; NREL/TP; 510-42618. 1617.

25. Ho, S.-H.; Huang, S.-W.; Chen, C.-Y.; Hasunuma, T.; Kondo, A.; Chang, J.-S. Bioethanol production using carbohydrate-rich microalgae biomass as feedstock. Bioresour. Technol. 2013, 135, 191-198. [CrossRef] [PubMed]

26. luiter A, H.B.; Ruiz, R.; Scarlata, C.; Sluiter, J.; Templeton, D. Determination of Ash in Biomass Laboratory Analytical Procedure (LAP); National Renewable Energy Laboratory: Golden, CO, USA, 2005.

27. Standard, T. Solvent Extractives of Wood and Pulp. In TAPPI T 204 cm-97; TAPPI Press: Atlanta, GA, USA, 1997.

28. Hongru Feng, J.Y.; Li, Q.I.N.; Mo, X.I.A.N. Expression of $\beta$-pinene synthase (QH6) in Escherichia coli for the biosynthesis of $\beta$-pinene. Chin. J. Bioprocess Eng. 2015, 13, 28-34.

29. Yang, J.; Zhao, G.; Sun, Y.; Zheng, Y.; Jiang, X.; Liu, W.; Xian, M. Bio-isoprene production using exogenous MVA pathway and isoprene synthase in Escherichia coli. Bioresour. Technol. 2012, 104, 642-647. [CrossRef] [PubMed]

Sample Availability: Samples of the compounds holocellulose, water, lipid, ash, protein are available from the authors.

(C) 2017 by the authors. Licensee MDPI, Basel, Switzerland. This article is an open access article distributed under the terms and conditions of the Creative Commons Attribution (CC BY) license (http:/ / creativecommons.org/licenses/by/4.0/). 